\title{
Empirical Analysis of Job Satisfaction Determinants in Russia
}

\author{
Andrei B. Ankudinov ${ }^{1}$, Oleg V. Lebedev ${ }^{1} \&$ Andrei A. Sachenkov $^{1}$ \\ ${ }^{1}$ Kazan Federal University, Kazan, Russian Federation \\ Correspondence: Andrei B. Ankudinov, Kazan Federal University, Kazan, Russian Federation. Tel: \\ 79-17-239-0323. E-mail: ankudia@mail.ru
}

Received: August 22, 2014 Accepted: November 7, 2014 Online Published: January 14, 2015

doi:10.5539/ass.v11n4p117 URL: http://dx.doi.org/10.5539/ass.v11n4p117

\begin{abstract}
Investigation into job satisfaction determinants is of high practical relevance since it acts as an indicator of particular groups of employees' willingness to invest in development of professional competencies and skills. The paper presents results of empirical analysis of determinants of job satisfaction, satisfaction with professional advancement prospects as well as concerns over possible job loss carried out using panel data representing working population of Russia. The main results obtained lead us to the following conclusions. Employment functions as well as financial incentives have the strongest influence over job satisfaction and satisfaction with professional advancement prospects, while respondents representing all professions reviewed are generally equally concerned with possible job loss. Age and length of respondent's employment are nonlinearly related to satisfaction indicators while gender differences are not significant. Residents of large cities are less frequently satisfied with their jobs and professional advancement prospects; however, they are much less concerned about possible job loss. Those employed by state-owned companies and agencies more frequently express satisfaction with their current positions. The analysis also reveals a distinct decline in job satisfaction level and in satisfaction with professional advancement opportunities in the crisis years of 2009 and 2010.
\end{abstract}

Keywords: job satisfaction, probit-model, job insecurity, panel data, Russia

\section{Introduction}

Empirical study of problems of job satisfaction is of key importance for labor economics. Among most important elements of employees' job satisfaction analysis one can single out investigation of factors affecting it. Definition, categorization and classification of those factors constitute the research subject of a significant number of theoretical as well as empirical studies. Practical importance of job satisfaction determinants analysis and identification lies in empowering corporate management to single out tools of improvement in productivity; in the literature there is certain evidence obtained by means of meta-analysis of positive relation between level of job satisfaction and labor productivity as well as company efficiency as a whole (Petty et al., 1984; Miller \& Monge, 1986; Judge et al., 2001; Harter et al., 2002). In the conditions of transformational economy like that of Russia, characterized by liquidity-constrained economic environment, job satisfaction management might act as an efficient tool of labor productivity improvement (Krueger, 2003; Linz, 2002). Russia's accession to WTO adds special importance to the study since the degree of employees' job satisfaction strongly affects their motivation to invest in specific capital which in turn has a strong influence over competitive advantages of a number of sectors of national economy (Ankudinov \& Lebedev, 2014).

First attempts to present the factors of employees' job satisfaction in a systematic way were made by psychologists in the 40-60-s of the twentieth century; the most widely known publications being those by A. Maslow and F. Herzberg. The problem has attracted economists' attention only in 1970-s. Modern studies of the problem are based on conducting interviews with employees and subsequent analysis of collected data using mathematical and statistical analytical tools. Almost all researches place special emphasis on such factors as gender, age, marital status, education and length of employment, while the analyses demonstrate rather controversial evidence with regard to what actual impact those factors have.

A number of relevant empirical results obtained recently for developing countries should be noted. Zawiah and Taha (2006) studied automotive industry employees in emerging markets. They conclude that age, gender, marital status and length of employment affect the level of job satisfaction. However, all these characteristics are not the key ones; they only determine the strength of the impact other variables have on level of employee 
satisfaction.

On the other hand, there are studies reporting that relation between job satisfaction level and the listed above characteristics is statistically insignificant (Amiri et al., 2010). At the same time some other determinants of job satisfaction level were established, such as relations with immediate supervisor, his or her professional competency; relations with colleagues, including friendliness of work environment, level of professional expertise, team work; career progression system, its availability, fairness, and transparency; nature and content of work, including perception of work as valuable and useful with visible resulting effect.

Sowmya and Panchanatham (2011) in their study conducted in India initially included 25 factors potentially capable to influence job satisfaction level. Then, using Likert response scale they singled out five most significant factors: pay and promotion, organizational factors (corporate culture, pride for the company-employer), relations with immediate supervisor, content of work, relations with colleagues.

Among the most recent publications dealing with job satisfaction analysis in emerging markets a study by Islam et al. (2012) can be singled out for investigation of factors specific to Bangladeshi market known for concentration of low-cost manufacturing. The authors select for analysis 9 factors; however only amount of compensation, career opportunities, company vision, content of work process and company healthcare and insurance policy demonstrate significant effect. The other factors - power and authority, relations with colleagues, company strategy and employees retirement policy-turned out to be insignificant in relation to job satisfaction.

Russian studies in the field of employee job satisfaction are as yet few in number. V. Patrushev et al. observe generally low level of job satisfaction on the part of Russian employees, citing amount of compensation, working conditions, labor management, relations with management as the reasons (Patrushev et al., 1998). By contrast Temnitski and Bessokirnaya demonstrate that while the majority of salaried employees are not satisfied with their wage rates and financial situations they are satisfied (to one extent or another) by their jobs (Temnitski \& Bessokirnaya, 1999). G. Monusova comes to the conclusion that generally low level of job satisfaction on the part of Russian employees to the larger extent is caused by the gap between preference structure, resulting from high levels of applicants education and jobs available (Monusova, 2008); the effect has been empirically substantiated for a number of branches of national economy (Ankudinov \& Lebedev, 2013).

A review of relevant literature leads to a conclusion that empirical evidence is quite controversial, especially when it comes to actual significance of particular factors potentially influencing levels of employees' satisfaction in different economic, legal, cultural and confessional environments. Even though many researchers select similar sets of variables (job characteristics) for consideration, the results appear to be highly sensitive towards a number of factors of different nature. Nontransparent and informationally inefficient markets of emerging economies add to the confusion since in many cases they fail to send early signals to labor market thus producing gross disproportions between the supply and demand sides. In a number of countries, including Russia, deeply rooted paternalistic attitudes on the part of the bulk of economically active population further complicate the analysis. Taking into account how long does it take to build up competitive qualifications and how short is amortization period of specific capital in knowledge-based economy, investigation of job satisfaction determinants becomes of especial importance for emerging economies, in search of sources of long-term and sustainable competitive advantages.

\section{Materials and Methods}

The research is based on the longitudinal study "The Russian Longitudinal Monitoring", which is a series of nationally representative surveys designed to monitor the effects of Russian reforms on the health and economic welfare of households and individuals in the Russian Federation. To account for unobserved heterogeneity of individuals (i.e. for factors, uncontrolled by the built models) and changes in variables over time as well as to expand the sample size we analyze panel data. On the basis of the seven annual waves of research for years 2004-2010 (Note 1) a sample was formed based on 3704 individuals with total sample consisting of 16005 observations, that is, on average, 4.3 observations falling on one individual. The latter figure can be explained by two factors: first, not all individuals participated in all waves of the research, and second, if at least one variable was missing from the data, the annual research results for the particular person were excluded from the sample altogether. Missing values is an inherent problem of large sets of panel data. However, estimates can still be consistent if missing data is of random character, which is the probability of non-availability is independent of the value of missing variables.

Descriptive statistics of variables used in modeling for the entire period is presented in Table 1. Indicators of job satisfaction, satisfaction with professional advancement opportunities and job security served as dependent variables. Just over half of the respondents turned out to be generally satisfied with their jobs while at the same 
time experience certain concerns about possible job loss. However, respondents less frequently speak about their satisfaction with professional advancement prospects (about 39\% of all responses).

All other variables presented in Table 1 served as independent variables in probit models; time dummies were represented by years of research.

Out of the whole sample, $42 \%$ of observations represent men; the "average" respondent is about 40 years old, with 8 years of work experience and 13 years of education. The average respondent's hourly after tax earnings are equal to 55.5 Roubles with 43 average weekly hours of work. Quadratic and logarithmic forms of a number of variables were introduced to account for possible nonlinear character of relationship. Approximately one-fifth of the respondents have subordinates. About $17 \%$ of respondents work in hazardous conditions, $57 \%$ are employed by state-owned companies or organizations, $42 \%$ are residents of large cities. Professional makeup of the sample can be estimated through average values of dummy variables of individual professions. As a reference time dummy the year 2004 was chosen (first year of the research included in the sample), while OCC7 (industrial workers) served as an occupational dummy. Substantial variability of variables should also be noted.

Since the dependent variables of job satisfaction, satisfaction with professional advancement opportunities and job security are binary, use of linear regressions may lead to biased estimates. In the analysis of binary variables the appropriate technique is Probit-modeling.

Table 1. Descriptive statistics, 2004-2010

\begin{tabular}{llll}
\hline Variable & Description & Mean & Std. Dev. \\
\hline SatWo & General job satisfaction (1=yes; 0=no) & 0.56 & 0.49 \\
SatGr & Satisfaction with professional advancement opportunities (1=yes; 0=no) & 0.39 & 0.48 \\
Worry & Concern over possible job loss (1=yes; 0=no) & 0.58 & 0.49 \\
Sex & Gender (male=1; female=0) & 0.42 & 0.49 \\
Age & Age of respondent & 40.45 & 11.85 \\
Age & Age squared & 1777.19 & 1004.99 \\
Exp & Years of work in current company & 8.21 & 9.32 \\
Exp ${ }^{2}$ & Years of work squared & 154.39 & 309.74 \\
Educ & Education years & 13.36 & 2.16 \\
HWage & Average hourly wages (after tax), in Roubles. & 55.50 & 49.07 \\
LnHWage & Nat Log of average hourly wages & 3.74 & 0.74 \\
WrkWk & Average weekly hours of work, in hours. & 42.87 & 11.2 \\
LnWrkWk & Nat Log of average weekly hours of work & 3.72 & 0.26 \\
Super & Existence of subordinates at the current position (1=yes; 0=no) & 0.22 & 0.41 \\
Cond & Hazardous character of production (1=yes; 0=no) & 0.17 & 0.37 \\
Gov & State ownership or state participation in equity capital (1=yes; 0=no) & 0.57 & 0.49 \\
Site & Type of settlement (large city, regional center=1; other=0) & 0.42 & 0.49 \\
Occupational dummies (according to Occupational Classification ISCO 88) & & \\
OCC1 & Lawmakers, high-ranking officials, executives & 0.04 & \\
OCC2 & Professionals with university degrees & 0.20 & \\
OCC3 & Professionals with post-secondary education & 0.18 & \\
OCC4 & Office and customer service clerks & 0.07 & \\
OCC5 & Service sector employees & 0.10 & \\
OCC7 & Craftsmen & 0.13 & \\
OCC8 & Industrial workers & 0.16 & \\
OCC9 & Unskilled workers & 0.12 & \\
\hline
\end{tabular}

Probit models are built on the basis of "from general to specific" method. Basing on this method the analysis starts with building a general "unrestricted" model which includes all available factors suggested by the relevant theory. Next stage of analysis involves estimation procedures of individual "restricted" models based on exclusion of insignificant variables. The competing models are then tested using the likelihood ratio test, LR. LR-statistics is calculated as follows: 


$$
L R=2\left[\log \left(L_{U R}\right)-\log \left(L_{R}\right)\right]
$$

where $\log \left(\mathrm{L}_{\mathrm{UR}}\right)$ and $\log \left(\mathrm{L}_{\mathrm{R}}\right)$ are the values of $\log$-likelihood of unrestricted and restricted models respectively. LR-statistics follows the $\chi_{k}^{2}$ distribution, where $\mathrm{k}$ is the number of excluded variables (restrictions).

The following general probit models for individual number $\mathrm{i}$ for the period $\mathrm{t}$ are built, with job satisfaction, satisfaction with promotion opportunities and job security concerns serving as dependent variables:

$$
\begin{aligned}
& y_{i t}=\beta_{0}+\beta_{1} \operatorname{Sex}_{i t}+\beta_{2} \text { Age }_{i t}+\beta_{3} \text { Age }_{i t}^{2}+\beta_{4} \operatorname{Exp}_{i t}+\beta_{5} \operatorname{Exp}_{i t}^{2}+\beta_{6} \text { Educ }_{i t}+ \\
& +\beta_{7} \text { HWage }_{i t}+\beta_{8} \text { WrkWk }_{i t}+\beta_{9} \text { Super }_{i t}+\beta_{10} \text { Cond }_{i t}+\beta_{11} \text { Gov }_{i t}+\beta_{12} \text { Site }_{i t} \\
& + \text { occupational_dummies }+ \text { time_dummies }+\varepsilon_{i t}
\end{aligned}
$$

Estimates of probit models' $\beta$ coefficients are obtained by maximum likelihood estimation (MLE) method. Due to nonlinear character of the probit model, the magnitude of changes in event probability which is associated with a given change of an independent variable depends on the values of all the other independent variables. Marginal effects of the variables under consideration presented in the analysis hold all other independent variables fixed at some average level. Formulae for calculation of $\beta$ and marginal effects of probit model with random effects can be found in (StataCorp, 2009, pp. 424-426). All calculations and data management are performed using the software package STATA12.0.

It should be also noted that most of analyzed variables vary insignificantly with the time (which is due to the very nature of the factors under investigation); therefore models with fixed effects are not considered here. Regressions with random effects are built up as well as pooled regressions. The appropriate models are tested using the Likelihood ratio (LR) test.

\section{Results}

Table 2 presents the results of restricted probit models with random effects, obtained by the maximum likelihood method. General models (i.e. models including all factors under consideration) are not presented here for the sake of brevity, however the relevant results can be provided by the authors upon request. Thuswise, from model 1, describing job satisfaction of employees, the following variables are excluded: number of years of education, hazardous working conditions and dummy variable for the year 2005. LR-statistics of joint significance of aforementioned variables amounts to 3.36 , while the critical value of $\chi 2$ distribution with three degrees of freedom at $10 \%$ significance level is equal to 6.25. Similarly, there are 6 factors excluded from model 2. Eleven variables are excluded from model 3 (most of them are occupational dummies, which indicates statistical insignificance of differences in levels of concern over possible job loss on the part of representatives of different kinds of occupation). The Wald statistics allows us to reject the zero hypothesis of joint insignificance of factors of all three restricted models, with high level of reliability: p-values of all models are less than 0.000 . The Rho ( $\rho$ ) coefficient, representing the share of the total dispersion contributed by panel level variance component demonstrates substantial influence of unobserved individual effects, such as personal values and ambitions, life stance, etc., over the empirical indicators under consideration.

Formally interpreting the probit estimates it can be noted that the probability of positive answer to the question about whether the respondent is satisfied with his o her job is approximately $9 \%$ higher for male respondents, all other factors held equal. At the same time gender differences in assessment of satisfaction with professional advancement opportunities statistically do not significantly differ from zero. However, men are less concerned about job loss (the probability is $14 \%$ lower).

Age differences quite distinctively manifest themselves in all three models, though the effect is moderate and the relation is nonlinear, while the variables are significant at $1 \%$ level. With increase in respondents' age job satisfaction level as well as satisfaction with professional advancement opportunities fall. However, in both cases the effect has rising tendency: starting approximately from 36 years of age $(|-0.057 /(2 * 0.0008)| \approx 36)$ every additional year of age increases the likelihood of positive answer to the question about job satisfaction, while starting from 38 the same is true for satisfaction with professional advancement opportunities. For example, increase in age from 50 to 51 years results in rise in the probability of respondent's satisfaction by his or her job by $-0.057+2 *(0.0008) * 51 \approx 0.025$. Besides, with increase in respondents' age their concern over possible job loss goes up; however, with diminishing influence of the variable. 
Table 2. Estimates of probit models with random effects (Note 2)

\begin{tabular}{|c|c|c|c|c|c|c|}
\hline \multirow{3}{*}{ Variable } & & \multicolumn{2}{|l|}{ SatGr } & \multicolumn{2}{|l|}{ Worry } \\
\hline & Model 1 & & Model 2 & & Model 3 & \\
\hline & $\begin{array}{l}\text { Marginal } \\
\text { effects }\end{array}$ & z-stat. & $\begin{array}{l}\text { Marginal } \\
\text { effects }\end{array}$ & z-stat. & $\begin{array}{l}\text { Marginal } \\
\text { effects }\end{array}$ & z-stat. \\
\hline Sex & 0.089 & $(2.13)^{*}$ & - & & -0.142 & $(3.47)^{* *}$ \\
\hline Age & -0.057 & $(6.24)^{* *}$ & -0.060 & $(7.30)^{* *}$ & 0.077 & $(7.91)^{* *}$ \\
\hline $\mathrm{Age}^{2}$ & 0.0008 & $(6.95)^{* *}$ & 0.0008 & $(7.44)^{* *}$ & -0.0008 & $(7.54)^{* *}$ \\
\hline Exp & -0.011 & $(2.26)^{*}$ & 0.004 & $(1.94)^{*}$ & 0.010 & $(1.90)$ \\
\hline $\operatorname{Exp}^{2}$ & 0.0003 & $(2.09)^{*}$ & - & & -0.0002 & $(1.44)$ \\
\hline Educ & - & & -0.015 & $(1.67)$ & -0.022 & $(2.59)^{* *}$ \\
\hline HWage & 0.007 & $(15.26)^{* *}$ & 0.005 & $(14.18)^{* *}$ & - & \\
\hline WrkWk & 0.004 & $(3.34)^{* *}$ & 0.006 & $(5.01)^{* *}$ & 0.003 & $(2.19)^{*}$ \\
\hline Super & 0.178 & $(4.42)^{* *}$ & 0.475 & $(12.01)^{* *}$ & - & \\
\hline Cond & - & & 0.084 & $(2.14)^{*}$ & -0.158 & $(3.81)^{* *}$ \\
\hline Gov & 0.116 & $(3.64)^{* *}$ & - & & - & \\
\hline Site & -0.080 & $(2.19)^{*}$ & -0.181 & $(4.88)^{* *}$ & -0.415 & $(10.34)^{* *}$ \\
\hline \multicolumn{7}{|l|}{ Time dummies } \\
\hline 2005 & - & & - & & 0.088 & $(2.44)^{*}$ \\
\hline 2006 & 0.206 & $(5.52)^{* *}$ & 0.170 & $(4.41)^{* *}$ & - & \\
\hline 2007 & 0.211 & $(5.49)^{* *}$ & 0.178 & $(4.53)^{* *}$ & - & \\
\hline 2008 & 0.254 & $(6.35)^{* *}$ & 0.168 & $(4.17)^{* *}$ & 0.224 & $(6.34)^{* *}$ \\
\hline 2009 & 0.238 & $(5.78)^{* *}$ & 0.326 & $(7.93)^{* *}$ & 0.162 & $(4.56)^{* *}$ \\
\hline 2010 & 0.167 & $(3.86)^{* *}$ & 0.090 & $(2.09)^{*}$ & 0.156 & $(4.23)^{* *}$ \\
\hline \multicolumn{7}{|l|}{$\begin{array}{l}\text { Occupational } \\
\text { dummies }\end{array}$} \\
\hline $\mathrm{OCC} 1$ & 0.464 & $(5.12)^{* *}$ & 0.372 & $(4.59)^{* *}$ & - & \\
\hline $\mathrm{OCC} 2$ & 0.431 & $(7.16)^{* *}$ & 0.414 & $(8.31)^{* *}$ & - & \\
\hline OCC3 & 0.404 & $(6.98)^{* *}$ & 0.265 & $(6.02)^{* *}$ & - & \\
\hline OCC4 & 0.176 & $(2.39)^{*}$ & - & & - & \\
\hline OCC5 & 0.152 & $(2.34)^{*}$ & - & & -0.121 & $(2.21)^{*}$ \\
\hline OCC7 & 0.124 & $(2.19)^{*}$ & - & & - & \\
\hline OCC9 & -0.123 & $(2.08)^{*}$ & -0.210 & $(4.02)^{* *}$ & - & \\
\hline Constant & 0.168 & $(0.87)$ & 0.043 & $(0.21)$ & -1.002 & $(4.46)^{* *}$ \\
\hline 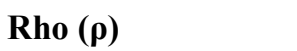 & 0.366 & $(28.07)^{* *}$ & 0.361 & $(27.77)^{* *}$ & 0.441 & $(34.37)^{* *}$ \\
\hline $\mathbf{N}$ & 16005 & & 16005 & & 16005 & \\
\hline Wald test & $\chi^{2}(22)=838.97 * *$ & & $\chi^{2}(19)=949.29 * *$ & & $\chi^{2}(14)=310.54^{* *}$ & \\
\hline LR test (exclusion) & $\chi^{2}(3)=3.36$ & & $\chi^{2}(6)=6.20$ & & $\chi^{2}(11)=2.97$ & \\
\hline
\end{tabular}

* significant at $5 \%, * *$ significant at $1 \%$

The effect of the length of respondent's employment on job satisfaction is statistically significant at $1 \%$ level; however, the influence is weak with the likelihood of positive answer first going down then rise within $1 \%$ limits. At the same time, increase in the length of respondent's employment is followed by rise in satisfaction with professional advancement opportunities: for example, 10 years of employment increase the likelihood of the satisfaction by $4 \%$. The quadratic form of the variable is insignificant and has been excluded from the model. Relation between the length of respondent's employment and his or her concern over possible job loss is direct ( $10 \%$ level of significance), though with diminishing effect (estimate is less reliable, exp2 variable is significant at $10 \%$ level using single-tail test. However, the influence of length of employment is weak and varies within $1 \%$ limits.

It appears that education levels of respondents are not among the determinants of job satisfaction, the variable is insignificant. It has to be noted here, that the job contents is formalized by occupational dummies which are obviously related to the education level variable. However, it does not cause the multicollinearity problem. At 
the same time, every 5 additional years of education bring the likelihood of respondent's satisfaction with his or her professional advancement opportunities down by approximately $8 \%$ (the variable is significant at $10 \%$ level) and concern over possible job loss by $11 \%$ (the variable is significant at $1 \%$ level). Results fall within the framework of theoretical reasoning: more educated respondents are more ambitious and resilient.

Average hourly after-tax wage rate variable acts as a potent and statistically reliable factor increasing likelihood of job satisfaction as well as satisfaction with professional advancement opportunities. Specifically, increase in hourly after-tax wages by 50 roubles results, ceteris paribus, in approximately $35 \%$ increase in the likelihood of positive answer to the question about job satisfaction and $25 \%$ increase in the likelihood of positive answer to the question about satisfaction with professional advancement opportunities. Variables are significant at $1 \%$ level As we can see, financial incentives indeed act as an important component of job satisfaction. However, the influence of wage rate over concerns over possible job loss does not statistically significantly differ from zero. All other factors held equal, low paid employees are equally concerned by possible loss of their current jobs as well paid ones.

Average workweek is positively related to the likelihood of satisfaction with the job, with professional advancement opportunities as well as to concerns over possible loss of current position (variables are significant at $1 \%, 1 \%$ and $5 \%$ level respectively). Specifically, increase in average workweek by 10 hours (which is quite a substantial addition amounting to approximately one standard deviation-see Table 1) results in an increase in likelihood of job satisfaction by approximately $4 \%$, satisfaction with professional advancement opportunities by $6 \%$ and concern over possible job loss by $3 \%$. As can be seen, the influence is quite weak. While interpreting the results obtained we assume that all variables are exogenous. However, though the length of workweek is generally established by employer according to national employment legislation, in certain cases employees themselves can have influence on weekly working hours, thus causing endogeneity problems. For example, the length of workweek might be a result of the employee's level of satisfaction with particular job, and not vice versa.

The very existence of subordinates substantially increases the likelihood of employee's satisfaction with current job and professional advancement prospects-by $18 \%$ and $48 \%$ respectively. Variables are significant at $1 \%$ level. At the same time the rank and file employees experience generally the same level of concern over possible job loss as their superiors, all other factors held equal.

Those working under dangerous and hazardous conditions are somewhat less concerned about the possible loss of their jobs, the probability being lower by $16 \%$ (1\% significance level), and more frequently speak about their satisfaction with professional advancement opportunities; the probability is higher by $8 \%$ ( $5 \%$ significance level) Employees of state-owned companies or organizations more frequently express satisfaction by their jobs (by $12 \%$ ), all other factors held equal. However, when it comes to satisfaction with professional advancement opportunities and concerns over possible job loss, there are no much differences between employees of state-owned and private companies.

Significant differences are observed in job satisfaction levels of employees in large cities and small settlements. Specifically, the likelihood of an employee in large city being satisfied with his or her job is $8 \%$ lower $(5 \%$ significance level), with professional advancement opportunities- $18 \%$ lower (1\% significance level). The results obtained provide certain empirical evidence supporting the theory put forward by financial behaviorists that people value their own well-being not in absolute terms, but relative to that of others. Obviously, the residents of large cities generally enjoy much wider opportunities for employment and promotion. However, the differentiation among the salaried employees is much higher too which results in higher levels of dissatisfaction. Large city residents are also much less concerned about possible loss of their jobs (the likelihood is $42 \%$ lower, with $1 \%$ significance level) for the evident reason of larger and more diversified supply of jobs in the labor market.

Due to recent financial crisis, already known as "Great Recession" (Note 3), the study of satisfaction indicators' change in time, with the influence of all other factors taken into account, is of substantial interest. 2004 is chosen as a criterion time-dummy; i.e. marginal effects are estimated against the 2004. As we can see, influence of the crisis is already evident in 2009: while up to 2008 constant growth in levels of job satisfaction could be observed, in 2009 and 2010 it gives way to sharp decline in relevant indicators.

It has to be pointed out that in the models under consideration the additional effects, resulting from the crisis (such as potential wage cuts, reduction in working hours, deterioration of working conditions as well as in quality of jobs, etc.) are hold fixed. As a result time-dummies serve as a proxy for general uncertainty among economic agents over the future, and according to the results of our analysis the isolated effect of this uncertainty 
is quite strong. However, the observed deterioration in respondents' estimates of professional advancement prospects happens with certain lag: in 2009 the likelihood of respondent's satisfaction with professional advancement opportunities is even higher than in 2008, but in 2010 the indicator dramatically goes down by $33-9=24 \%$ as compared to 2009 (5\% significance level). This fall in satisfaction with professional advancement prospects virtually obliterates progressive growth in respondents' positive estimates from 2004 onwards.

Strong influence over the likelihood of respondent's satisfaction with his or her job has professional occupation, with industrial workers occupational dummy serving as a criterion dummy variable. According to the results obtained, ceteris paribus, the likelihood of respondents being satisfied with their jobs is approximately $46 \%$ higher for high-ranking officials and managers, $43 \%$ higher for university graduates and $40 \%$ higher for specialists with specialized secondary education (variables significant at $1 \%$ level). Office clerks, service sector employees and craftsmen are also more satisfied by their jobs than industrial workers (by approximately $18 \%$, $15 \%$ and $12 \%$ respectively with variables significant at $5 \%$ level). As compared to industrial workers it is only unskilled workers who are less satisfied by their jobs (by 12\%).

As for the likelihood of satisfaction with career advancement opportunities, it is higher for high-ranking officials approximately by $37 \%$, for university graduates by $41 \%$ and for specialists with specialized secondary education by $21 \%$ (variables significant at $1 \%$ level). As compared to industrial workers it is only unskilled workers who are less satisfied by professional advancement opportunities (the probability is lower by $21 \%$ ). Other professional groups rather insignificantly differ in their degrees of satisfaction with professional advancement opportunities; the differences statistically insignificantly differ from zero. When it comes to concerns over possible job loss, representatives of almost all professions display generally the same level of concern, with the exception of the service sector employees, where the relevant indicator is $12 \%$ lower than that of industrial workers, all other factors held equal ( $5 \%$ significance level).

\section{Discussion}

The results obtained are generally in line with earlier empirical studies of job satisfaction and perceived level of economic security of employees. In particular, the dominant effect of economic incentives on job satisfaction and satisfaction with professional advancement prospects, empirically confirmed in this study, is consistent with results of previous studies, notably, that of Judge et al. (2010) where on the basis of meta-analysis the authors demonstrate existence of relation between level of job satisfaction and wage rate.

According to the studies based on International program of social monitoring data Russia is at the bottom of the list of European countries by the level of job satisfaction. Among the factors most negatively affecting job satisfaction of Russians low wage rates are singled out (Temnitski \& Bessokirnaya, 1999; Desai \& Idson, 2000; Linz, 2003).

Earlier studies have also demonstrated that job characteristics such as content of work process and working conditions are among the most powerful factors of job satisfaction (Monusova, 2008; Yang, 2009; Khalid et al., 2011) which is also in line with the results of this research.

As for the individual characteristics of employees, empirical literature presents some evidence of gender differences in job satisfaction levels; however, they are significant only for employees in their advanced years (Clark, 1997; Scandura \& Lankau, 1997). On the contrary, we document statistically significant gender differences in job satisfaction levels for all age groups. As for the relation between job satisfaction levels and economic insecurity on the one hand and age of the respondent on the other, our estimates are consistent with those of earlier studies (Lorence \& Mortimer, 1985; Varca et al., 1983; Linz, 2003). The obtained estimates of relation between levels of economic insecurity and levels education of employees are consistent with earlier results as well (Lincoln \& Kalleberg, 1985).

Earlier studies also demonstrate that both content of work process and individual characteristics of employees act as important determinants of levels of economic insecurity perceived by employees as well as of the incentives to invest in their professional development (Ankudinov \& Lebedev, 2014), while level of economic insecurity is related to occupational imbalances of skilled personnel in different sectors of national economy (Ankudinov \& Lebedev, 2013). In particular, less educated unskilled employees, women, residents of rural areas feel more exposed (Linz \& Semykina, 2010).

Though our findings at large are consistent with those obtained earlier for developed as well as developing countries, transformation process in Russian economy is not over yet and values of the Soviet period are still shared by many employees (Clarke, 1999; Krueger, 2003).

On the practical level our conclusions can serve as an important indicator of the extent to which particular 
workforce groups are prepared to invest in formation of professional skills and competencies which in turn might contribute to essential competitive advantages of national businesses. Under the conditions of Russia's accession to WTO the results concerning influence of respondent's level of education, gender as well as type of settlement where the respondent resides are especially important. If we assume that due to inherited from the years of planned economy low level of regional economic diversification communities in such regions would suffer most as a result of intensification of global competition, it is the commitment of most active part of their residents to invest in professional development as a derivative from job satisfaction level which comes to the forefront.

A number of limitations of the performed analysis have to be noted. Dependent variables such as level of job satisfaction and perceived level of economic insecurity are formed on the basis of respondents' own estimates and as a result can to a certain extent suffer from the endogeneity effect. Aggregated nature of occupational variables has to be also noted. Besides, regressions identify the correlation itself, but not the causality.

\section{Conclusion}

In the study we have investigated factors of respondents' satisfaction with their jobs, professional advancement opportunities and concerns over possible loss of current positions. Degrees of job satisfaction and satisfaction with professional advancement opportunities appear to be strongly influenced by nature of the job, size of remuneration, existence of subordinates. Relation between employee's age and length of employment on the one part, and degree of job satisfaction on the other is nonlinear; however the influence of the factors is quite weak: the likelihood of positive answer first goes slightly down then rise with increasing rate. The opposite effect is observed for the influence of age and length of employment over concerns about possible job loss: the relation is positive with diminishing rate. The type of settlement in which the respondent resides is also of substantial importance: residents of large cities are less satisfied with their jobs and career prospects, but at the same time are much less concerned about possible loss of job. The analysis also reveals a distinct decline in job satisfaction level and in satisfaction with professional advancement opportunities as well as rising concerns about the potential loss of jobs in the crisis years of 2009 and 2010.

\section{References}

Amiri, M., Khosravi, A., \& Mokhtari, A. (2010). Job satisfaction and its influential factors. Journal of Research in Health Sciences, 10(1), 42-46.

Ankudinov, A. B., \& Lebedev, O. V. (2013). Empirical analysis of employees with tertiary education occupational imbalances. American Journal of Applied Sciences, 10(10), 1134-1139. http://dx.doi.org/10.3844/ajassp. 2013.1134.1139

Ankudinov, A. B., \& Lebedev, O. V. (2014). Job insecurity and employees` motivation to engage in professional education. American Journal of Applied Sciences, 11(5), 860-865. http://dx.doi.org/10.3844/ajassp.2014. 860.865

Clark, A. (1997). Job satisfaction and gender: Why are women so happy at work? Labour Economics, 4(4), 341-372. http://dx.doi.org/10.1016/S0927-5371(97)00010-9

Clarke, S. (1999). The formation of a labour market in Russia. Northampton MA: Edward Elgar Publishing.

Desai, P., \& Idson, T. (2000). Work without wages: Russia's nonpayment crisis. Cambridge MA: MIT Press.

Hackman, J. R., \& Oldham, G. R. (1975). Development of the job diagnostic survey. Journal of Applied Psychology, 60(2), 159-170. http://dx.doi.org/10.1037/h0076546

Harter, J., Frank, L., \& Hayes, S. (2002). Business-unit-level relationship between employee satisfaction, employee engagement, and business outcomes: A meta-analysis. Journal of Applied Psychology, 87(2), 268-279. http://dx.doi.org/10.1037/0021-9010.87.2.268

Islam, M., Rasul, M., \& Wali Ullah, G. M. (2012). Analysis of the factors that affect job satisfaction: A case study on private companies employees of Bangladesh. European Journal of Business \& Management, 4(4), $35-46$.

Judge, T. A., Piccolo, R. F., Podsakoff, N. P., \& Shaw, J. C. (2010). The relationship between pay and job satisfaction: A meta-analysis of the literature. Journal of Vocational Behavior, 77(2), 157-167. http://dx.doi. org/10.1016/j.jvb.2010.04.002

Judge, T. A., Thoresen, C. J., Bono, J. E., \& Patton, G. K. (2001). The job satisfaction-job performance relationship: A qualitative and quantitative review. Psychological bulletin, 127(3), 376-407. http://dx.doi.org /10.1037/0033-2909.127.3.376

Khalid, K., Salim, H., \& Loke, S. P. (2011). The key components of job satisfaction in Malaysia water utility 
industry. Journal of Social Sciences, 7, 550-556. http://dx.doi.org/10.3844/jssp.2011.550.556

Krueger, G. (2003). Between two fires: Russian industry in transition. St Martin's Press.

Lincoln, J., \& Kalleberg, A. (1985). Work Organization and workforce commitment: A study of plants and employees in the U.S. and Japan. American Sociological Review, 50, 738-760. http://dx.doi.org/10. $2307 / 2095502$

Linz, S. (2002). Ownership and employment in Russian industry: 1992-1995. International Journal of Manpower, 23(1), 32-61. http://dx.doi.org/10.1108/01437720210421295

Linz, S. (2003). Job satisfaction among Russian workers. International Journal of Manpower, 24(6), 626-652. http://dx.doi.org/10.1108/01437720310496139

Linz, S., \& Semykina, A. (2010). Perceptions of economic insecurity: Evidence from Russia. Economic Systems, 34(4), 357-385. http://dx.doi.org/10.1016/j.ecosys.2010.02.006

Lorence, J., \& Mortimer, J. (1985). Job involvement through the life course: A panel study of three age groups. American Sociological Review, 50, 618-638. http://dx.doi.org/10.2307/2095378

Miller, K., \& Monge, P. (1986). Participation, satisfaction and productivity: A meta-analytic review. Academy of Management Journal, 29(4), 727-753. http://dx.doi.org/10.2307/255942

Monusova, G. A. (2008). Job satisfaction: International comparisons. World Economy and International Relations, 12, 74-83.

Patrushev, V. D., Bessokirnaya, G. P., \& Temnitski, A. L. (1998). Employees at the private firm: Motivation, salary and job satisfaction. Sociological Inquiries, 4, 34-41.

Petty, M. M., McGee, G., \& Cavender, J. (1984). A meta-analysis of the relationships between individual job satisfaction and individual performance. Academy of Management Review, 3, 712-721. Retrieved from http://www.jstor.org/stable/258493

Scandura, T. A., \& Lankau, M. (1997). Relationships of gender, family responsibility and flexible work hours to organizational commitment and job satisfaction. Journal of Organizational Behavior, 18(4), 377-391. http://dx.doi.org/10.1002/(SICI)1099-1379(199707)18:4<377::AID-JOB807>3.0.CO;2-1

Sowmya, K. R., \& Panchanatham, N. (2011). Factors influencing job satisfaction of banking sector employees in Chennai, India. Journal of Law and Conflict Resolution, 3(5), 76-79.

StataCorp. (2009). Stata longitudinal data reference manual: Release 11.0. Texas: StataCorporation.

Temnitski, A. L., \& Bessokirnaya, G. P. (1999). Life satisfaction and job satisfaction. Sociology Journal, 1/2, 188-194.

Varca, P., Shaffer, G., \& McCauley, C. (1983). Sex differences in job satisfaction revisited. Academy of Management Journal, 26(2), 348-353. http://dx.doi.org/10.2307/255982

Yang, J. T. (2009). Antecedents and consequences of job satisfaction in the hotel industry. International Journal of Hospitality Management, 29, 609-619. http://dx.doi.org/10.1016/j.ijhm.2009.11.002

Zawiah, S., \& Taha, D. Z. (2006). The effect of job and environmental factors on job satisfaction in automotive industries. International Journal of Occupational Safety and Ergonomics, 3, 267-280.

\section{Notes}

Note 1. Exclusion of earlier than 2004 waves of research from the analysis is caused by absence in the questionnaires for the years before 2004 of some essential variables used in the analysis.

Note 2. Definition of variables is presented in Table $1 ; *$ significant at $5 \%,{ }^{* *}$ significant at $1 \%$.

Note 3. Even by a quick glance at the stock markets, acting as a barometer of economic activity, one can establish the starting point of financial crisis in Russia: while the historic maximum (of about 2500 points) of RTS index was reached in May 2008, from the end of the 2008 summer steep decline of the index had begun, coming down to 550 points towards the end of October.

\section{Copyrights}

Copyright for this article is retained by the author(s), with first publication rights granted to the journal.

This is an open-access article distributed under the terms and conditions of the Creative Commons Attribution license (http://creativecommons.org/licenses/by/3.0/). 